\title{
Biorientation of Chromosomes in Cell Division Protein 1-Like 1
}

National Cancer Institute

\section{Source}

National Cancer Institute. Biorientation of Chromosomes in Cell Division Protein 1-Like 1. NCI Thesaurus. Code C150178.

Biorientation of chromosomes in cell division protein 1-like 1 (3051 aa, 330 kDa) is encoded by the human BOD1L1 gene. This protein plays a role in promoting the repair of damaged replication forks. 